\title{
RESENHA
}

\section{Procurando entender a morte}

\author{
Maria Dulce de França \\ Universidade Federal de Santa Catarina e UNIPLAC, Lages \\ Silvio Paulo Botomé \\ Universidade Federal de Santa Catarina
}

KOVÁCS, Maria Júlia et al. (2002). Morte e Desenvolvimento Humano. São Paulo: Editora Casa do Psicólogo: São Paulo. 253 p.

O que há de interessante em pesquisar sobre a morte? E sobre a relação com a morte? O que esse fenômeno encerra de curioso ao longo dos tempos e dos ensinamentos deixados à humanidade por Sófocles, Shakespeare, Dostoievski, Freud, Jung e tantos estudiosos até os contemporâneos? Investigar sobre a morte implica analisar suas incontáveis representações e nessa perspectiva vale a pena ler a obra, coordenada por Maria Julia Kovács, "Morte e Desenvolvimento Humano" que trata esse evento como um processo imbricado na própria vida.

Segundo a autora, esse livro, fruto dos debates ocorridos nas aulas de Psicologia da Morte, disciplina por ela criada em 1996, no Instituto de Psicologia da USP, fornece subsídios aos estudantes de Graduação em Psicologia, aos profissionais da saúde e a quaisquer pessoas cujo objetivo seja buscar informações sobre o fenômeno morte como parte integrante do desenvolvimento humano. Kovács investiga o entendimento e a relação com a morte nas abordagens: psicanalítica, junguiana e fenomenológica.

As representações mais comuns entre morte e desenvolvimento humano surgem a partir da mais tenra idade, quando a criança vivencia as primeiras ausências da mãe, ainda que por breves momentos. No entanto, à medida que se processa o desenvolvimento afetivo e emocional, ela tenta compreender o que se passa ao redor. Já na adolescência, segundo Kovács, período em que vida e morte alcançam sua plenitude, o jovem, movido pelo ímpeto de aventura, torna-se extremamente vulnerável à morte. A passagem para a vida adulta, porém, demanda um assentamento de toda essa impulsividade. É nesse momento, pois, que a morte lhe aparece como uma possibilidade pessoal, provocando a busca ou a preocupação de um significado para a vida.

Para Kovács, o medo da morte tão presente no ser humano, leva-o à incessante busca da imortalidade, cujos rituais, no Ocidente e no Oriente, explicam as diferentes formas de entender o nascimento e a morte. Salienta a autora que o processo de luto é conseqüência dos vínculos afetivos estabelecidos, porém, em casos de luto patológico é necessário o tratamento psicoterápico. Chama ainda a atenção sobre a necessidade de preparação dos profissionais de saúde para lidar com a morte no seu cotidiano.

Em sua obra, a autora evoca alguns estudos que merecem ser conhecidos. Rosenberg é um deles, por colocar em estudo experimental sobre envelhecimento e morte das pessoas, enfatiza a vida e a morte como partes de um mesmo processo. Carvalho constata que estados emocionais são geradores de doenças 
orgânicas, entre elas o câncer. Teorizando sobre a morte, Cassorla indica leituras complementares perfeitamente acessíveis a leigos. Na perspectiva da Psicologia Analítica de Carl Gustav Jung, Freitas apresenta considerações sobre o ser humano entre a vida e a morte fundamentadas em experiências relatadas por indivíduos recuperados de um estado de inconsciência. Da mesma forma, estudos clínicos realizados por Rothschild e Calazans contribuem, significativamente, para o entendimento do processo da morte numa perspectiva fenomenológicoexistencial.

Assim, em suas diferentes instâncias, a morte e o desenvolvimento humano têm sido tema de inesgotáveis pesquisas e teorias. Nessa linha de estudos estão relacionados nomes que vão da Antigüidade aos dias de hoje. Nos últimos tempos surgiu a contribuição de Maria Júlia Kovács e seus colaboradores, cujos estudos têm o objetivo de proporcionar aos profissionais de saúde e a quaisquer pessoas mais segurança, seja no âmbito pessoal, seja no dia-a-dia do seu trabalho. O livro "Morte e desenvolvimento humano" merece ser lido por todo profissional que, de alguma forma, lida no seu cotidiano profissional com a morte ou com as relações com a morte.

\section{Sobre os autores da resenha:}

Maria Dulce de França: Programa de Pós-Graduação em Psicologia da Universidade Federal de Santa Catarina/UFSC -

UNIPLAC/Lages. Endereço eletrônico: dulcefranca@bol.com.br

Silvio Paulo Botomé: Departamento de Psicologia da Universidade Federal de Santa Catarina/UFSC. 